\title{
AIRWAY OBSTRUCTION IN CHILDREN
}

\author{
Wg Cdr TS RAGHU RAMAN*, Sq Ldr DALJT SINGH+, \\ Dr DG JAYAPRAKASH\#, Col LN RAJA**
}

\begin{abstract}
Seventeen children presenting with airway obstruction have been studied to highlight the similar clinical features of different etiological conditions, their diagnostic limitations, and the importance of early bronchoscopy. There were 8 patients with foreign body in lower airway, out of which 6 were vegetable foreign bodies. Few rarer conditions like membranous laryngotracheobronchitis, subglottic hemangioma and acyanotic congenital heart disease producing airway obstruction have been highlighted. There were 2 deaths in the study unrelated to endoscopic procedure.
\end{abstract}

MJAFI 1995; $51: 87-90$

KEY WORDS : Airway obstruction; Bronchoscopy.

\section{Introduction}

7 he lower airways, especially those of children are dark and distant, relatively inaccessible and often mysterious. Airway size constraints and physiologic considerations have placed restrictions on the technique employed to derive information about the airways of pediatric patients. Direct visual exploration of the airways by endoscopy is frequently very desirable, not only for visual information, but also for obtaining specimens from the lower airways.

This presentation highlights the different clinical entities resulting in lower airway obstruction, their presenting features, and diagnostic and therapeutic endoscopic intervention.

\section{Material and Methods}

This study is based on children admitted to the pediatric ward of Command Hospital (Air Force) during the period from January 91 to December 92. Any child admitted with symptoms suggestive of airway obstruction like sudden onset of dyspnoea, persistent cough, choking, and chronic cough were included in the study. Detailed history taking and clinical examination was done in every child. Laboratory investigations included complete blood counts, radiological assessment of cervical region and thorax, and culture studies of secretions from the airway. Endoscopic examination and intervention using pediatric-size rigid and flexible bronchoscopes was carried out under general anaethesia. The procedure was repeated in case of persistence of symptoms and signs. All the children were followed up in the out-patient clinic.

\section{Observations}

During the study period, 17 children presented with features of airway obstruction. There were 11 males and 6 females. The distribution of cases as per the final diagnosis and their age and sex is shown in Table 1.

The clinical presentation in children with foreign body in the bronchus is summarised in Table 2.

History of foreign body aspiration was elicited in three cases. All but one child did have dyspnoea on admission. Cough as a symptom was present in 7 out of 8 cases. Reduced air entry was noticed in 4 children. Except in one case auscultation revealed crepitations and rhonchi.

\footnotetext{
${ }^{\star}$ Reader, Department of Pediatrics, AFMC, Pune 411040 ; +Graded specialist (Pediatrics); \#Postgraduate student (Pediatrics); * Senior Advisor (Pediatrics) CH (AF), Bangalore 560007.
} 
Two cases of membranous laryngotracheobronchitis presented with high fever, toxicity, inspiratory stridor, and hoarseness of voice. Symptoms in children with laryngotracheobronchitis were sudden onset of dyspnoea,

TABLE 1

Disease pattern in children with airways obstruction (n=17)

\begin{tabular}{|c|c|c|c|}
\hline $\begin{array}{l}\text { Case } \\
\text { no i }\end{array}$ & $\begin{array}{c}\text { Age } \\
\text { in years }\end{array}$ & Sex & Diagnosis \\
\hline 1. & 4 & M & Foreign body bronchus (right) \\
\hline 2. & 2.5 & $\mathbf{F}$ & Mucus plug (left) \\
\hline 3. & 2 & $\mathbf{M}$ & Foreign body bronchus (right) \\
\hline 4. & 3 & $\mathbf{M}$ & Foreign body bronchus (left) \\
\hline 5. & 1.5 & $\mathrm{~F}$ & Foreign body bronchus (right) \\
\hline 6. & 5 & $\mathbf{F}$ & $\begin{array}{l}\text { Acyanotic congenital heart } \\
\text { disease }\end{array}$ \\
\hline 7. & 4.5 & M & $\begin{array}{l}\text { Membranous laryngotracheo- } \\
\text { bronchitis }\end{array}$ \\
\hline 8. & 2 & $\mathrm{~F}$ & Foreign body bronchus (right) \\
\hline 9. & 0.75 & M & Laryngotracheobronchitis \\
\hline 10. & 1.5 & $\mathbf{M}$ & Foreign body bronchus (right) \\
\hline 11. & 3.75 & $\mathbf{F}$ & Middle lobe syndrome \\
\hline 12. & 4 & M & Subglottic haemangioma \\
\hline 13. & 1.75 & M & Foreign body bronchus (left) \\
\hline 14. & 3 & $\mathrm{~F}$ & Foreign body bronchus (right) \\
\hline 15. & 5 & M & $\begin{array}{l}\text { Membranous laryngotracheo- } \\
\text { bronchitis }\end{array}$ \\
\hline 16. & 4 & $\mathbf{M}$ & Middle lobe syndrome \\
\hline 17. & 0.9 & M & Laryngotracheobronchitis \\
\hline
\end{tabular}

stridor, retraction of chest, and restlessness. The child with acyanotic congenital heart disease presented with recurrent episodes of cough, tachypnoea, and chest retraction. The 4-year-old with subglottic hemangioma presented with history of stridor since early infancy and had developed acute respiratory distress prior to admission. Two cases of middle lobe syndrome presented with history of chronic cough, loss of weight, fever, and had not been immunised with BCG.

The radialogic signs seen were (i) unilateral emphysema in 4 out of 6 cases with foreign body in bronchus; (ii) atelectasis of left lower lobe in the child with congenital acyanotic heart disease (Fig 1); (iii) consolidation right middle lobe syndrome (Fig 2); (iv) pneumonic infiltration; (v) narrowing of subglottic region in cases of membranous laryngotracheobronchitis and subglottic haemangioma.

The bronchoscopic findings were (i) foreign bodies (five were bits of groundnuts, 1 custard apple seed, 1 of multiple stones, and 1 unidentified foreign body); (ii) narrowing of left lower bronchus with visible pulsation under the wall, in the child with congenital acyanotic heart disease. (This child was a known case of ventricular septal defect with severe pulmonary hypertension) (iii) narrowing of right middle lobe bronchus with debris.

TABLE 2

Clinical features in children with foreign body bronchus ( $n=8$ )

\begin{tabular}{lcccll}
\hline $\begin{array}{l}\text { Age } \\
\text { in } \\
\text { years }\end{array}$ & $\begin{array}{c}\text { History of } \\
\text { foreign body } \\
\text { aspiration }\end{array}$ & Dyspnoea & Cough & $\begin{array}{c}\text { Symptoms \& Signs } \\
\text { Air entry }\end{array}$ & $\begin{array}{l}\text { Crepitations \& } \\
\text { rhonchi }\end{array}$ \\
\hline $\mathbf{4}$ & + & + & - & reduced (Rt) & + Rt \\
2 & - & + & + & normal & + bilateral \\
3 & + & - & + & normal & + bilateral \\
1.5 & - & + & + & reduced (Lt) & + Lt \\
2 & - & + & + & reduced (Lt? & + bilateral \\
1.5 & + & + & + & reduced (Rt) & + bilateral \\
$\mathbf{1 . 7 5}$ & - & + & + & normal & - \\
3 & & + & normal & + bilateral \\
\hline
\end{tabular}

Key : + = present; - = absent; Rt = right; Lt =left 


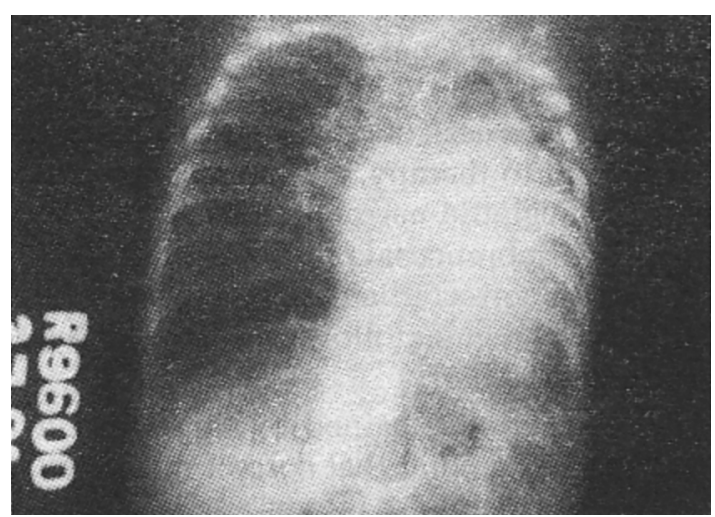

Fig. 1 : Atelectasis left lower lobe in a child with congenital acyanotic heart disease.

(Both cases proved to be cases of progressive primary complex). (iv) subglottic narrowing with purulent secretions (positive for Staph aureus); (v) subglottic narrowing with submucosal swelling; (vi) significant mucosal edema and secretions were present in all cases.

Children with a diagnosis of foreign body bronchus underwent therapeutic bronchoscopy after necessary preoperative preparation including intravenous fluids, oxygen and antibiotics. Two children required second bronchoscopy for removal of multiple foreign bodies. Out of the 8 cases of foreign body bronchus, one child aged 4 years died during postoperative period. Other children showed uneventful recovery.

Cases of membranous laryngotracheobronchitis were treated with high doses of antibiotics, oxygen, and humidity. The child with subglottic heamangioma had to undergo tracheostomy to relieve acute hypoxia. Both cases of middle lobe syndrome were diagnosed as progressive primary complex and started on antitubercular drugs and short course of steroids. The child with congenital acyanotic heart disease with repeated episodes of atelectasis of left lower lobe succumbed to acute on chronic congestive cardiac failure. Autopsy confirmed extrinsic compression of left lower lobe bronchus by the greatly dilated left main pulmonary artery.

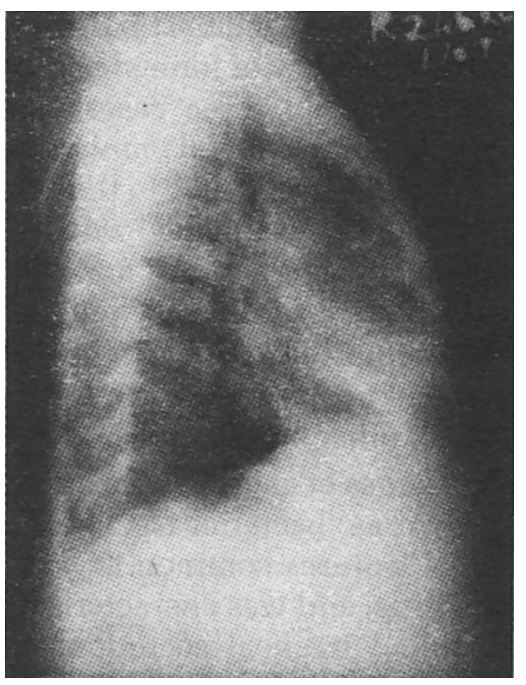

Fig. 2 : Consolidation right middle lobe.

\section{Discussion}

On encountering a child with acute respiratory distress a pediatrician has to assess the severity of the condition, establish the diagnosis and quickly relieve the causative factor. Experience is required to tackle this common emergency. A vital role is also played by the endoscopist and the anaesthetist without whom successful management is not possible.

Studies of large series of foreign body aspirations have revealed that about $70 \%$ patients are children, and one third of these had foreign bodies lodged in the airway. [1] The incidence of foreign body aspiration is higher in the age group below 4 years because children of this age group either do not know what belongs in their mouth or cannot adequately manage what goes into the mouth. Infants frequently swallow objects of fascination such as coins, buttons and pins. Children in the age group of two to four years cannot chew food finely. Therefore nuts and other vegetable foreign bodies are frequently aspirated into the airway.

Diagnosis of foreign body in the airway is based on positive history, high index of suspicion, and radiological signs such as 
radio-opaque foreign body, unilateral emphysema, atelectasis, and mediastinal shift. In the present study, history of foreign body aspiration was elicited in three cases only, and radiologic sign of unilateral emphysema was seen in four cases. Diagnosis in the rest of the patients could be established only after repeated clinical examinations, and the use of early endoscopic examination and a high index of suspicion. Difficulties in the diagnosis of foreign body aspiration have been amply illustrated in other studies [2,3].

In 1979, James et al brought to attention an entity known as 'bacterial tracheitis' which had clinical features common to both croup and epiglottitis, and was characterised by copious purulent tracheal secretions, marked subglottic edema and a normal epiglottis [4]. Now redesignated as membranous laryngotracheobronchitis, this potentially life threatening rare condition has been reported only once from this country [5].

Acute laryngotracheobronchitis affects the entire laryngotracheobronchial tree and is always of viral etiology. The inflammation of the subglottic region, the narrowest portion of the airway in infants, however produces the classical sign of croup. The loosely attached mucosa in the subglottic region readily allows submucosal edema formation and subsequent airway narrowing [6].

Compression of an airway by a markedly enlarged heart may produce atelectasis in infants and young children with acyanotic congenital heart disease. The distended pulmonary arteries and enlarged left atrium result in airway obstruction. The most common sites affected are the left upper bronchus, left main bronchus and middle bronchus [7]. Enlarged hilar lymph nodes similarly produce extramural compression of the middle lobe bronchus. Some researchers have referred to this predisposition as the right middle lobe syndrome. The usual cause in children is tuberculosis $[8,9]$.

Subglottic haemangioma, usually seen in girls and presenting in early infancy with stridor and hoarseness of voice is again a rare condition. The child in the present study was admitted as a case of croup. However failure to respond to therapy, and endoscopic findings of subglottic narrowing associated with unilateral submucosal reddish swelling indicated the correct diagnosis. Tracheostomy followed by regular follow up allows for natural regression [10].

The experience gained by this study has reinforced the point that correct diagnosis of airway obstruction in infants and young children is limited by the mimicking nature of symptoms and signs, unreliable or difficult to demonstrate radiological signs. An early endoscopic procedure is important. Chevaliar Jackson, the father of bronchoscopy stated that in case of doubt as to whether bronchoscopy should be done or not, bronchoscopy should always be done.

\section{REFERENCES}

1. Holinger $\mathrm{LD}$. Foreign bodies of the larynx, trachea, and bronchi. In : Bluestone (editor). Pediatric Otolaryngology. 2nd ed, Philadeplphia : WB Saunders, 1990; 1206-14.

2. Lakshman K, Santhanakrishnan BR. Foreign bodies in the tracheo bronchial tree in children : Diagnostic problems and management. Indian J Pediatr 1987; 54 :765-8.

3. Sharma AK, Agarwal LD, Prabhakar G, Gupta A, Sharma C, Chandra S. Therapeutic and diagnostic role of bronchoscopy in pediatric age group. Indian Pediatr 1992; 29 : 287-90.

4. Jones R, Santos JJ, Overall JC. Bacterial Tracheitis. J Am Med Assoc 1979; 242 : 721-6.

5. Singhi S, Singh RP, Kumar L, Walia BNS. Bacterial tracheitis. Indian Pediatr 1989; 26 : 390-6.

6. Gressman M. Diagnosis and management of croup and epiglottitis. Pediatr Clin North Am 1994; 41 : 265-76.

7. Kravitz RM. Congenital malformations of lung. Pediatr Clin North Am 1994; 41 : 453-72.

8. Livingstone GL, Holinger LD, Luck SR. Right middle lobe syndrome in children. Int J Pediatr Otorhinolaryngol 1987; $13: 11-14$.

9. Intrathoracic tuberculosis and miliary spread. In : Miller FJW, editor. Tuberculosis in children. 1st edn, Edingburgh, Churchill Livingstone, 1982; 105 : 36.

10. Richardson MA, Cotton RT. Anatomic abnormalities of pediatric airway. Pediatr Clin North Am 1984; 31 : 821-34. 